\title{
The Challenge to Observe Antarctic Toothfish (Dissostichus mawsoni) under Fast Ice
}

\author{
Davide Di Blasi ${ }^{1,2}, *$, Simonepietro Canese ${ }^{3,4}$, Erica Carlig ${ }^{1}$, Steven J. Parker ${ }^{5}$, Eva Pisano ${ }^{1}$, Marino Vacchi ${ }^{1}$ \\ and Laura Ghigliotti ${ }^{1}$ D
}

1 Institute for the Study of Anthropic Impacts and Sustainability in Marine Environment-National Research Council, via De Marini 6, 16149 Genoa, Italy; erica.carlig@ias.cnr.it (E.C.); eva.pisano@ias.cnr.it (E.P.); marino.vacchi@ias.cnr.it (M.V.); laura.ghigliotti@cnr.it (L.G.)

2 Department of Earth, Environmental and Life Sciences, University of Genoa, 16149 Genoa, Italy

3 Stazione Zoologica Anthon Dohrn, 80100 Naples, Italy; simonepietro.canese@szn.it

4 Italian Institute for Environmental Protection and Research, 00185 Rome, Italy

5 National Institute of Water and Atmospheric Research Ltd, 7010 Nelson, New Zealand; steve.parker@niwa.co.nz

* Correspondence: davide.diblasi@ias.cnr.it

check for updates

Citation: Di Blasi, D.; Canese, S.; Carlig, E.; Parker, S.J.; Pisano, E.; Vacchi, M.; Ghigliotti, L. The Challenge to Observe Antarctic Toothfish (Dissostichus mawsoni) under Fast Ice. J. Mar. Sci. Eng. 2021, 9, 255. https://doi.org/10.3390/ jmse9030255

Academic Editor:

Francesco Tiralongo

Received: 23 January 2021

Accepted: 25 February 2021

Published: 28 February 2021

Publisher's Note: MDPI stays neutral with regard to jurisdictional claims in published maps and institutional affiliations.

Copyright: (c) 2021 by the authors. Licensee MDPI, Basel, Switzerland. This article is an open access article distributed under the terms and conditions of the Creative Commons Attribution (CC BY) license (https:// creativecommons.org/licenses/by/ $4.0 /)$.

\begin{abstract}
In situ observation of Antarctic toothfish (Dissostichus mawsoni) is challenging as they typically live at depths greater than $500 \mathrm{~m}$, in dark and ice-covered Antarctic waters. Searching for adequate methodologies to survey Antarctic toothfish in their habitat, we tested a miniaturized Baited Remote Underwater Video camera (BRUV), deployed through holes drilled in the sea ice in the Ross Sea region, over three field seasons. In 2015 three BRUVs were deployed at McMurdo Sound, and paired with a vertical longline sampling. In 2017, three opportunistic deployments were performed at Terra Nova Bay. In 2018 seven deployments at Terra Nova Bay provided preliminary data on the habitat preferences of the species. The design and configuration of the mini-BRUV allowed to collect high-quality video imagery of 60 Antarctic toothfish in 13 deployments from the fast sea ice. The behaviour of fish at the bait, intra-species interactions, and potential biases in individual counting were investigated, setting baselines for future studies on the abundance and distribution of Antarctic toothfish in sea-ice covered areas. This work represents the first step towards the development of protocols for non-extractive monitoring of the Antarctic toothfish in the high-Antarctica coastal shelf areas, of great value in the Ross Sea region where the largest MPA of the world has recently been established.
\end{abstract}

Keywords: BRUV; Ross Sea; video sampling; Antarctica

\section{Introduction}

The Antarctic toothfish (Dissostichus mawsoni) is the largest notothenioid fish inhabiting Antarctic continental waters, where it is a keystone species in the food web as a high-trophic-level predator. Since 1998, this species has been targeted by commercial fisheries in the Ross Sea (conventionally defined by the $60^{\circ} \mathrm{S}$ parallel, $150^{\circ} \mathrm{E}$ and $150^{\circ} \mathrm{W}$ meridians, and the corresponding coastline of Antarctica) managed by the Commission for the Conservation of Antarctic Marine Living Resources (CCAMLR), according to an ecosystem-based precautionary approach (www.ccamlr.org, accessed on 24 February 2021). Such an approach requires broad understanding of the species' life history and ecology as foundation for management [1]. For Antarctic toothfish, biological and ecological information has mostly been collected by observers onboard of commercial fishery vessels in offshore, deeper, and ice-free waters [2,3].

In the Ross Sea region, a large Antarctic toothfish population has been identified based on genetics and mark-recapture studies [2]. The population spans a wide geographic range from the spawning habitats in northern areas of the Pacific Antarctic Ridge to the 
feeding grounds on the continental slope, and juvenile habitats in the deeper zones of the continental shelf [3-5]. However, while data on size, distribution, diet and reproductive status of Antarctic toothfish from vessel-based surveys exists, it does not cover the full extent or ecological niche of the species seasonally or spatially, as vessel-based data is confined to ice free waters in summer and autumn.

Since 2018, with the implementation of the Ross Sea region Marine Protected Area (Ross Sea region MPA, CCAMLR Conservation Measure 91-05), the continental shelf has been closed to commercial fishing, further limiting information from this area, and constraining the ability to monitor the effect of the MPA. While coastal areas of the Ross Sea shelf are the main locations where toothfish are preyed upon by their main predators, Weddell seals (Leptonychotes weddellii) and Killer Whales (Orcinus orca), these fast-ice covered areas are neglected by monitoring, and few information is currently available on the Antarctic toothfish population dynamics in those areas [6-10]. Surveying through the sea ice requires large holes made through ice more than 2-m thick to take out large toothfish [8]. This is time consuming and requires the use of large and heavy equipment, both characteristics making such an extractive methodology logistically demanding in high Antarctica and limiting survey activities over large areas. To enable monitoring of Antarctic toothfish in fast-ice-covered shelf areas, innovative methods need to be developed to overcome logistical constraints, including non-extractive methods for working in the MPA.

Non-extractive methods for the study of marine fauna include acoustic and visual techniques. Underwater acoustics is largely used for studying zooplankton as well as pelagic species, but it is not effective for organisms that reside or move close to the bottom [11], such as the Antarctic toothfish, as the vertical resolution, especially at the appropriate depths, can obscure several metres of demersal habitat, and targets need to be identified from acoustic characteristics [12,13]. Conversely, underwater video techniques allow to record abundance and distribution of target species both in the water column and close to the bottom, where targets can be visually identified. Additional benefit of video sampling is the ability to observe behaviour, habitat association as well as intra- and inter-species relationships (see [11] for a review).

Among the video techniques, the Baited Remote Underwater Video systems (BRUVs) methodology is conceptually simple and based on a recording video camera that documents the arrival of organisms attracted to a baited lander [14,15]. Such a technique, which minimizes observer biases and gear selectivity associated with other survey methods, is likely appropriate for fish such as the Antarctic toothfish, characterized by good olfactory capabilities [16] and with benthic scavenger feeding habits [17]. BRUVs allow video documentation of species presence, size, and behaviour (e.g., swimming speed, feeding mode, searching). Relative abundance metrics can also be developed [18], provided that the bias associated with counting individuals that enter the field of view multiple times is accounted for [19].

Since the mid-1990s, BRUVs have been used in temperate, tropical and subtropical areas, mostly to assess the effect of Marine Protected Areas, document species behaviour, or assess changes in fish assemblages [11,20,21]. In polar waters, BRUVs have been less employed so far. BRUVs were used in the marine waters of the northern Canadian territory of Nunavut [22,23]. Very few baited camera deployments were performed in the Southern Ocean prior to present work, none in high Antarctica. An autonomous lander was deployed around South Georgia and Falkland Island to estimate the abundance of the congeneric Patagonian toothfish (Dissosticus eleginoides) independently from the fishery catch data [24]. A BRUV was set by SCUBA diver in shallow waters at Adelaide Island (West Antarctic Peninsula) to study the response of scavengers to feeding cues in the area [25]. Within Ryder Bay, in the West Antarctic Peninsula, a baited camera system was used to examine the distribution of scavenging fauna in relation to the spatial variation in exposure to iceberg scouring [26]. In those cases, the BRUVs were large in size and/or needed to be set underwater by a SCUBA diver, both characteristics unsuitable for work in sea-ice covered areas and at over $500 \mathrm{~m}$ depth. 
Here, we conducted a trial of the feasibility, efficacy and reliability of a mini BRUV to study the Antarctic toothfish in fast ice-covered shelf areas. In the frame of collaborative researches between New Zealand and Italy, a pilot study was undertaken during three Antarctic field seasons, at two different locations (nearby-located to the New Zealand and the Italian Antarctic research stations that gave logistic support to make the study possible) within the Western Ross Sea region. The study aimed to (i) investigate the Antarctic toothfish behaviour at the bait and evaluate its potential influence on the calculation of relative abundance metrics, (ii) test the reliability of the results obtained by BRUV by comparison with those collected by extractive techniques, and (iii) set baselines for future studies on the distribution and abundance of the species in shelf areas.

The work promotes the diffusion of such a non-extractive technique for monitoring and sampling within the Ross Sea region MPA and sets the bases for use of BRUVs in other areas around the Antarctic continent.

\section{Materials and Methods}

\subsection{Study Area and Sampling}

The work was part of New Zealand-Italian collaborative activities conducted at McMurdo Sound, near the New Zealand's Scott Base in November 2015, and Terra Nova Bay, near the Italian Mario Zucchelli Station in November 2017 and 2018.

\subsubsection{General Description of the Study Area}

The fast-ice study area is located in the western Ross Sea (Figure 1A) with a mean depth of about 500 meters and bathymetry associated with local volcanos and scouring by glacial ice. The shape of the seafloor and depth direct tidal currents comprised Ice Shelf Water (ISW) and the water produced beneath the freezing sea ice (Ross Sea Shelf Water, RSSW). In the spring months, currents are usually less than $10 \mathrm{~cm} \mathrm{~s}^{-1}$ and flow in a north-south direction [27].

All deployments were made through the 1.5-2.5 m thick fast sea ice that covers the sea surface for 9-10 months a year, from March until January. The holes extended through the platelet ice layer, a feature unique to coastal Antarctic zones [28,29]. Two locations were sampled, McMurdo Sound and Terra Nova Bay (Figure 1B). The former is a long depression up to $1000 \mathrm{~m}$ deep extending from the Ross Ice Shelf and bordering Ross Island [27]. The latter is along the Victoria Land coast and is a steep seafloor consisting of granitic rock ridges and gullies filled with gravel, clay, and silt [27,30]. Deployments in Terra Nova Bay were performed in Silverfish Bay which, within the vast Ross Sea region MPA, also constitutes an Antarctic Specially Protected Area (ASPA 173) of the Antarctic Treaty.

\subsubsection{Mini-BRUV}

One of the main points for consideration when working in Antarctica is logistics. With sampling sites spanning over a large area, the constraints in the transportation, included those deriving by the use of helicopters, need to be considered. Accordingly, the BRUV system was designed to be light and portable to optimize loads during transport. Furthermore, the size of the BRUV was minimized in order to allow deployments from relatively small holes in the sea ice, thus avoiding carrying around the large and heavy equipment that would be necessary to drill large holes and saving time.

The mini-BRUV system consisted of two cylindrical housings made of Delrin ${ }^{\circledR}$ POM (DuPont ${ }^{\mathrm{TM}}$ ) of $70 \mathrm{~mm}$ external diameter and $250 \mathrm{~mm}$ in length. At the end of one cylinder was a $15 \mathrm{~mm}$ thick, flat acrylic camera and light sensor port. The other end contained a flat Delrin plate with a Seacon Electrical Wet-Mate bulkhead connector. The cylinder held a full HD Mobius camera (with a $64 \mathrm{~Gb}$ memory card and an Arduino Micro microcontroller board), and a NiMH battery pack. The other cylinder of the same size held a MR16 LED lamp ( 6 Watt, 12 Volt, cool white), and a dedicated NiMH battery pack. The two cylinders were fixed in parallel and connected by cable (Figure 2). 

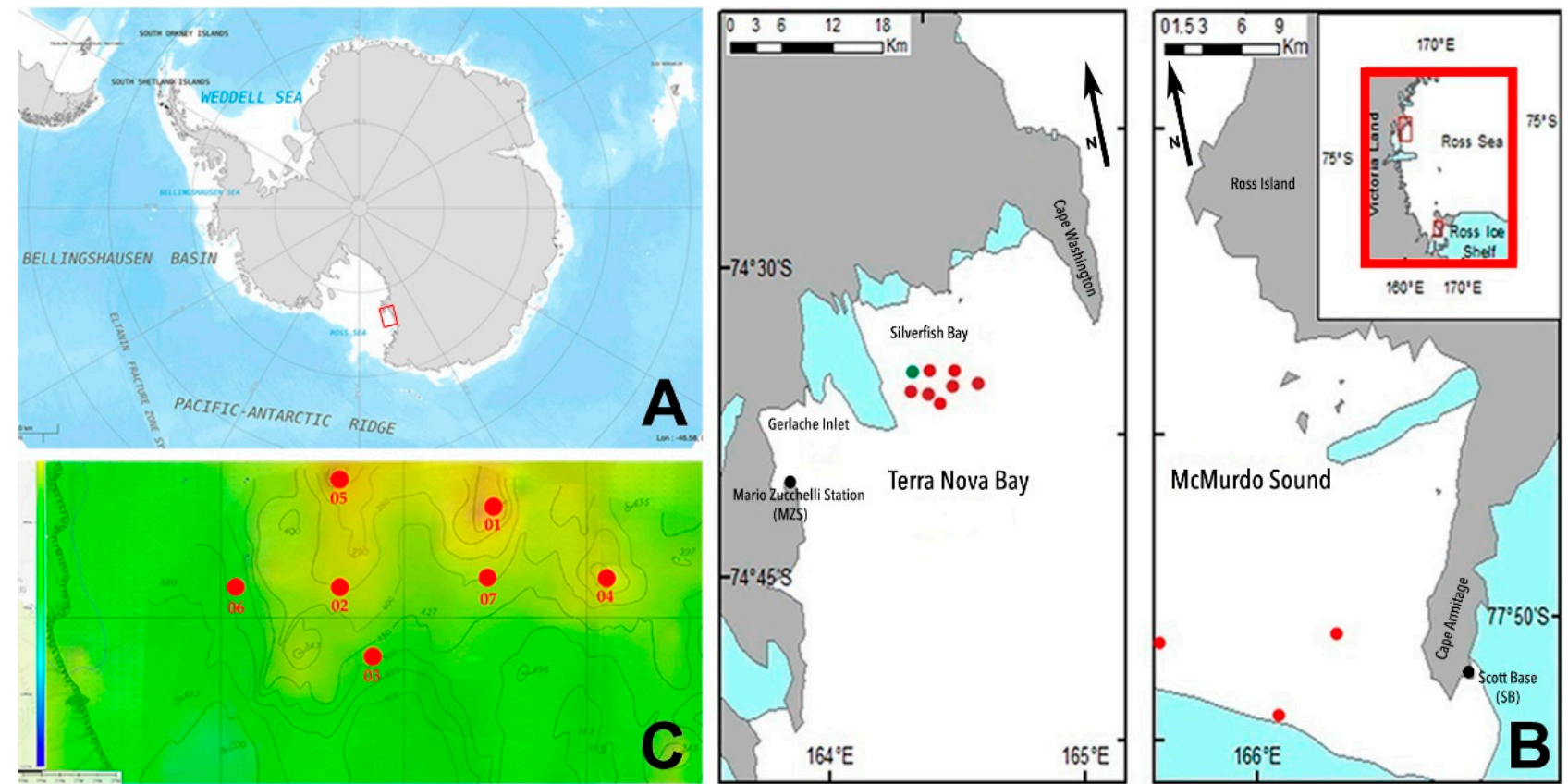

Figure 1. The study area. (A) Location of the study area within Antarctica continental shelf (red frame); (B) Sampling sites at Terra Nova Bay (left) and McMurdo Sound (right). Ice tongues or ice shelves are marked in light-blue colour; lands are marked in grey; white colour corresponds to seawater, partly covered by sea ice during the sampling periods. The sampling stations are in areas covered by fast ice in the late spring. Red dots indicate the sites sampled in 2018 at Terra Nova Bay (left) and in 2015 at McMurdo Sound (right). The green dot corresponds to the sampling site at which the BRUV was opportunistically deployed in 2017, three times with the bait and two times without the bait. (C) Bottom geomorphology at Silverfish Bay (Terra Nova Bay), the red dots are the seven sampling sites where Baited Remote Underwater Video camera (BRUV) deployments were carried out in 2018.

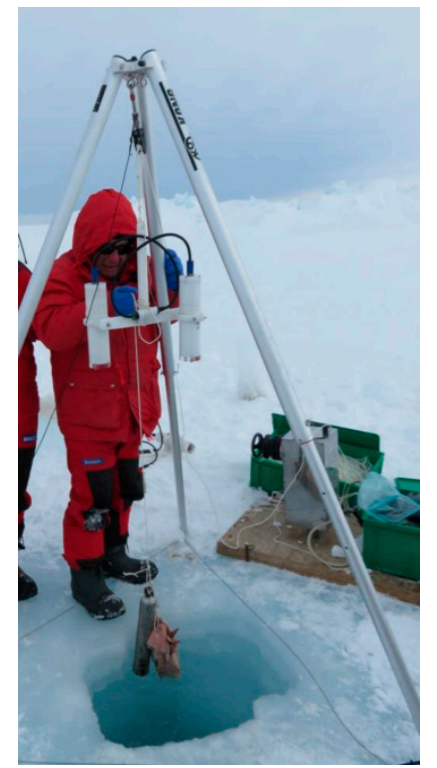

Figure 2. Essential structure of the mini-BRUV system. The prototype was deployed through ice holes of about $40 \mathrm{~cm}$ diameter.

The Arduino microcontroller was programmed to switch the camera and light "on" or "off". During the first year of field activity, at McMurdo Sound, the camera was set to perform one minute of registration and one minute of pause to optimize the battery duration. Given the good performance of the batteries in this first trial, the protocol was adjusted during the field activities at Terra Nova Bay, where registration was continuous. 
Approximately $1 \mathrm{~kg}$ of squid (Notodarus gouldi), routinely used in the Antarctic toothfish longline fishery, was used as the bait. It was fixed $2 \mathrm{~m}$ below the camera, just above the 8 $\mathrm{kg}$ clump weight. Three $150 \mathrm{~mm}$ diameter trawl floats (800 $\mathrm{g}$ buoyancy each) were placed above the mini-BRUV to adjust buoyancy and suspend it $2 \mathrm{~m}$ above the clump weight. The camera configuration was vertical with the view towards the seafloor, resulting in a field of view of about $2 \mathrm{~m}$ in diameter. The system was slowly lowered with a $3 \mathrm{~mm}$ nylon rope to the seafloor by hand or with a winch.

\subsubsection{Sampling Design}

The study included the following three lines of investigation, covering major aspects related to the use of BRUV systems to monitor Antarctic toothfish in ice-covered areas.

1. Toothfish behaviour at the bait

Three BRUV deployments were performed at McMurdo Sound (2015) and ten at Silverfish Baywithin Terra Nova Bay (three at the same station in 2017, and seven at different stations in 2018) (Figure 1B,C). In addition, in 2017, the mini-BRUV was deployed twice at Silverfish Bay without bait, as negative control to evaluate the attractive effect of the bait.

The residence time, how long on average a specimen remains in the vicinity of the bait (from first appearance to last appearance in the case of individuals that keep coming back into the field of the camera), was calculated in the 10 continuous videos performed at Terra Nova Bay during 2017 and 2018. Behaviour at the bait was evaluated as potential source of bias in the count of toothfish by BRUV [19]. When more than one individual was present in the camera field of view, the behaviour of each one was annotated and classified as "neutral", "agonistic aggressor" or "agonistic subordinate". For each agonistic event, the behaviour of both the aggressor and the subordinate fish were noted and described as follows: "stay", when the fish did not appear altered by the event; "weak reaction", when the fish reacted with rapid movements and appeared disturbed or when it escaped but returned under the field of view after a few seconds; "escape", when the fish moved away and did not return in proximity of the bait. The size of the individuals involved in the different events was included in the analysis.

\section{Comparison between BRUV data and longline catch}

This activity was implemented at McMurdo Sound in 2015, where a scientific random stratified vertical longline survey was being conducted from the sea ice, as part of a large-scale monitoring programme [10]. The aim of this first field activity was to perform preliminary tests on the reliability of the BRUV systems in collecting Antarctic toothfish abundance data. To this end, three longline fishing stations (namely Station 20, 28, and 29 , details in [10]) were considered. At each station, vertical longlines, armed with 15/0 size hooks (EZ-baiter, Mustad) baited with squid, were set three times for approximately $18 \mathrm{~h}$ each. The mini-BRUV was deployed at the three longline fishing stations, once per each station. The camera deployments were opportunistically performed after the retrieval of one of the longlines and before the deployment of the subsequent longline set, thus resulting in BRUV soak times ranging between 19 and $24 \mathrm{~h}$. The number of individuals recorded by BRUV in a determined time of unit was compared to the vertical longline catch, expressed as average catch obtained from three replicate fishing events per station.

3. Habitats and distribution of Antarctic toothfish individuals

A preliminary study, aimed at investigating the relation between physical characteristics of the sea bottom, depth and presence of Antarctic toothfish, was performed in 2018 at Terra Nova Bay. The study included BRUV deployments at seven stations in Silverfish Bay. The stations were representative of different geomorphological features (ridge and trench) and falling in a range of bottom depths from about $200 \mathrm{~m}$ to more than $500 \mathrm{~m}$. Soak time ranged between 1 to $6 \mathrm{~h}$, depending on the contingencies of the time allowed for field activity and the weather. Information on relief, substrate type, and benthos coverage of the 
seafloor was recorded for each station. Depth was measured by echosounder during the video recording. The substrate type and the coverage by benthic organisms were evaluated through image analysis of the sea floor. Sediment granularity was not easily distinguishable from video footages. Therefore, we classified the substrate as "soft" when the seafloor was homogenously composed by clay, silt or sand, and "mixed" when rocky formations were visible. The benthos coverage was defined as percentage of seafloor surface in the field of view of the camera covered by epibenthic organisms. Examples of seafloor features are shown in Figure 3.
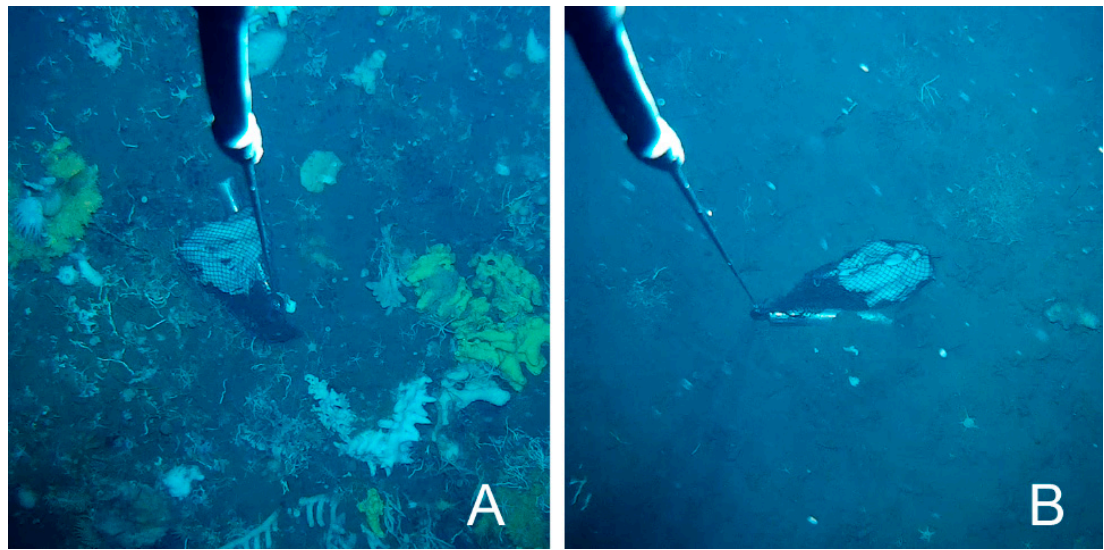

Figure 3. Examples of seafloor features. (A) Mixed substrate with high (90\%) benthos coverage (Terra Nova Bay, site 05). (B) Soft substrate with low (10\%) benthos coverage (Terra Nova Bay, site 06).

\subsection{Video Analysis}

Videos were screened in full with VLC Media Player 3.0.5 Vetinari Software. Identification of individual Antarctic toothfish was performed by extracting frames each time a toothfish was within the field of view and establishing individual and unambiguous key features such as colour patterns, parasites, scars, or other recognizable marks (Figure 4).

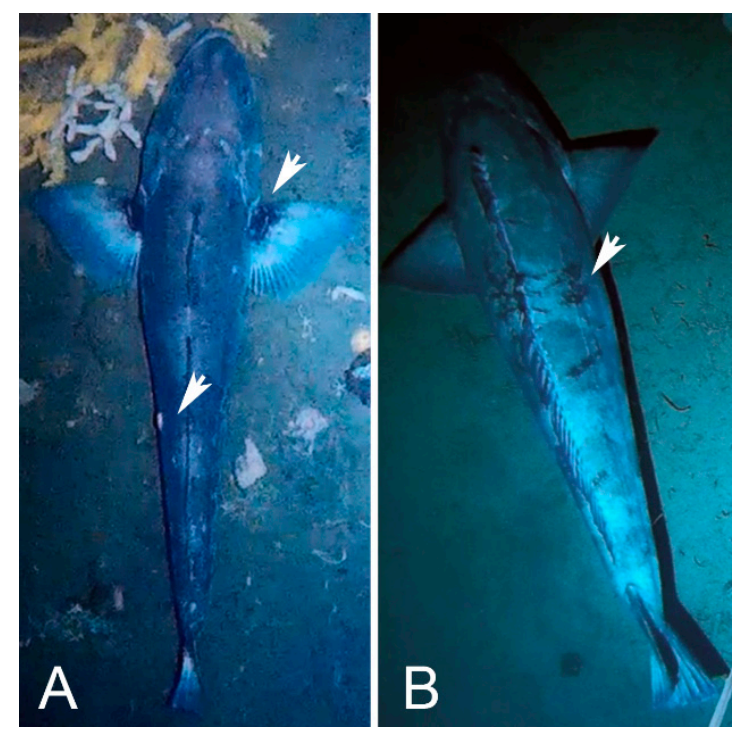

Figure 4. Examples of identifying marks on toothfish individuals. (A) Distinctive colour pattern of the pectoral fins and presence of a parasite on the left side of the trunk. (B) Dark spot pattern along the body.

Image J software was used to estimate the total length. For each individual identified, the length of the fish was calculated by comparison with the cylindrical weight on the seafloor ( $33 \mathrm{~cm}$ long) when they were both at a similar distance from the camera. In order 
to minimize the effect of potential errors in the measurements, we categorised the fish length into three length classes following [3], corresponding to immature $(\mathrm{L}<100 \mathrm{~cm})$, maturing $(\mathrm{L}=100-130 \mathrm{~cm})$, and mature fish $(\mathrm{L}>130 \mathrm{~cm})$.

\subsection{Abundance Indices}

Relative abundance metrics, typically calculated from BRUV footages, were derived from videos recorded in 2018 at Terra Nova Bay.

The Catch Per Unit of Effort (CPUE) is an index widely used in fishery research. It was adapted to the BRUV analyses [31,32] and calculated as the total number of fish recorded, divided by the time of the video recording, and expressed as number of individual fish observed per hour. CPUE is not widely used in BRUV analysis, because unbiased value requires to identify each individual fish that enter the field of view of the camera during the entire observation period. This is especially difficult where large numbers of individuals are present, as it is often the case in shallow tropical or temperate waters, or for species whose individuals are not easily distinguishable. Given the relatively low densities of toothfish, and the possibility to identify individuals, potential bias in the use of CPUE is limited; therefore, we decided to consider this metrics.

The Mean Number (MeanN) [33], commonly used for dense and/or multispecies shoals of fish [34-44], was calculated from the maximum number of fish in a single frame from the whole video (Maximum Number, MaxN). While the advantage of this metric is to avoid recounts of same individuals [45] without the necessity to identify each individual, it can under-estimate the true abundance of fish visiting the bait, given that only a portion of the fish contribute to MaxN [46]. Therefore, we decided to consider also the MeanN, that is the average of the mean MaxN from 1-hour periods throughout the duration of the recording [33]. For the calculation of MeanN, final segments videos shorter than $1 \mathrm{~h}$ were discarded.

The Time of First Arrival (TFA) [47,48] was calculated as the time in minutes that passed from when the BRUV reached the seafloor and the first record of an Antarctic toothfish that entered in the field of view of the camera.

The correlation between metrics was tested through Pearson's correlation coefficient, and the relative abundance of Antarctic toothfish deriving from the various metrics was considered in the frame of a suite of environmental drivers (geomorphological features, depth, substrate type, and benthos coverage).

\section{Results}

\subsection{Fish Behaviour}

A total of 60 toothfish were observed during the 13 deployments carried out between McMurdo Sound and Terra Nova Bay. The residence time of individuals around the bait, calculated for 52 individuals during the continuous video recordings at Terra Nova Bay, was highly variable with mean residence time of $8 \mathrm{~min} 24 \mathrm{~s} \pm 9 \mathrm{~min} 36 \mathrm{~s}$ SD (maximum $44 \mathrm{~min}$, minimum $10 \mathrm{~s}$ ). No toothfish were recorded when the BRUV was deployed without the bait. Of the observed fish, 44 were recorded close to the bait together with at least another individual in the same frame (Video S1). Most toothfish (25 individuals) were neutral to the presence of other individuals within the field of view; two individuals left the field of view without any intra-specific interaction; one was apparently involuntarily bitten by another individual and had a weak escape reaction, swimming away and returning a few seconds later; two fish increased the swimming speed in the field of view after inadvertent contact; and in 13 cases evident agonistic behaviour were recorded (Figure 5).

A descriptive analysis was developed on the 13 cases that showed agonistic events from the combination of the type of event, size classes involved, and subsequent reactions (Figure 6). In 5 cases (38.5\%), the larger individuals behave as aggressors; in 5 other cases, aggressors were of the same size class of the subordinates; and 3 times (23.1\%) the smaller individuals were the aggressors. The aggressors never left, and either showed weak reactions (regardless of the size of the fish attacked) in 3 cases or remained near the 
bait (10). The subordinates in 2 cases escaped and did not return (in both they were of the same size class of the aggressor), but in most cases they showed weak reactions and remained near the bait (Video S1).

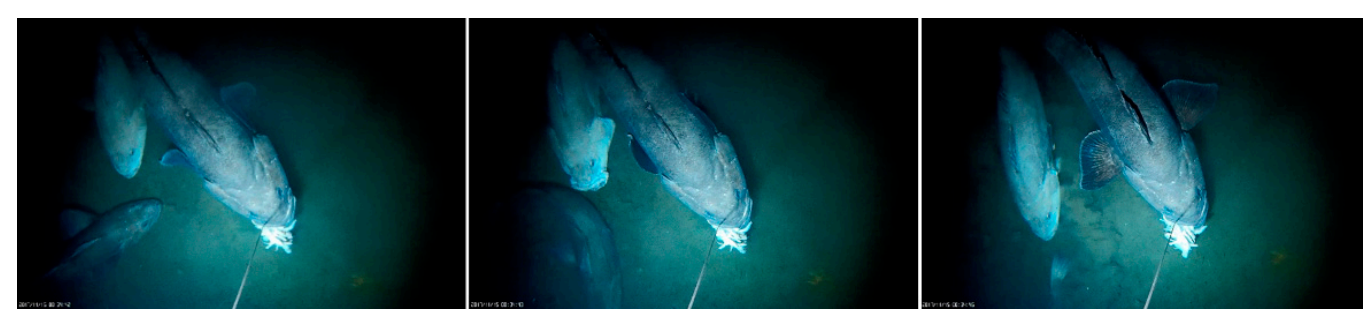

Figure 5. Sequence of an agonistic event. Two toothfish are involved (left side of the images) on the side of a third individual which is eating the bait. Video recorded at Site 06, Terra Nova Bay.
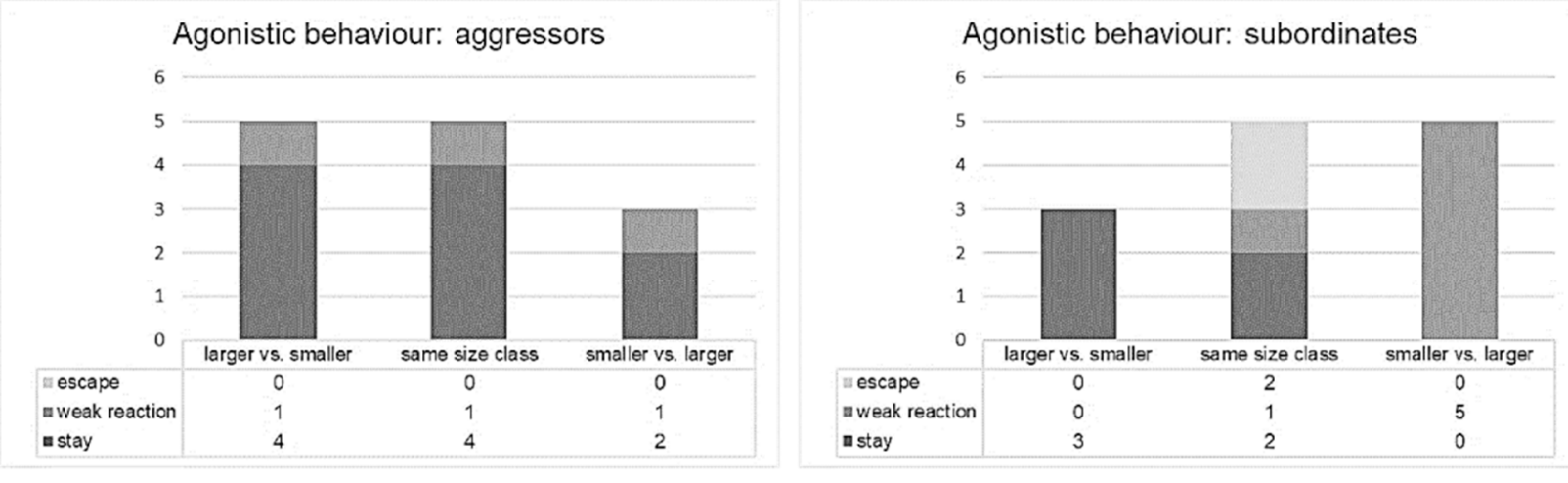

Figure 6. Reaction of aggressors and subordinates in the 13 recorded agonistic events, according to the size of the involved individuals.

\subsection{BRUV Data and Longline Catch}

Sampling was performed in McMurdo Sound on the shelf area from 537 to $579 \mathrm{~m}$ depth (Table 1), at sites characterized by soft substrate bottom (Table S2). While BRUV was deployed for approximately $20 \mathrm{~h}$ at each station, in two out of the three cases, the bait was consumed prior to the end of the deployment, about one hour and after about four hours, respectively. Given the key role of the bait in this sampling system, portions of the video recorded in absence of the bait were discarded, and for the sake of standardization, the analysis of all videos was limited to the first hour of setting.

Table 1. McMurdo Sound, total number of fish recorded with BRUV during the first hour of setting at each station, and average vertical longline (VLL) catch values obtained from three deployments at each station.

\begin{tabular}{ccc}
\hline Station \# & Fish Recorded & VLL Catch (Mean \pm SD) \\
\hline 20 & 5 & $13.0 \pm 2.6$ \\
28 & 3 & $13.7 \pm 5.5$ \\
29 & 0 & $6.3 \pm 5.9$ \\
\hline
\end{tabular}

During the first hour of the three video samplings, eight Antarctic toothfish were observed. Five $(62.5 \%)$ were assigned to the immature size class, and three $(37.5 \%)$ were maturing individuals.

\subsection{Sea Bottom Features, Depth, and Toothfish Abundance}

A total of 18 Antarctic toothfish were recorded in four out of seven BRUV samplings carried out in 2018 at Terra Nova Bay (Table S2). Most fish were in the maturing size class 
( $n=10,55.6 \%)$, but mature $(n=5,27.7 \%)$ and immature fish $(n=3,16.7 \%)$ were also sighted. Eight out of ten maturing toothfish were recorded at a depth higher than $500 \mathrm{~m}$ (Site 06).

At sites where no toothfish were recorded, the substrate was mixed and with high percentages of benthos coverage, while in 3 out of 4 sites in which toothfish arrived to the bait, the substrate was soft and the benthos coverage low, as for McMurdo Sound. While toothfish were sighted in correspondence of ridges shallower than $400 \mathrm{~m}$ depth, the highest abundances were recorded in a trench habitat, at more than $500 \mathrm{~m}$ depth (Table 2).

Table 2. Environmental variables considered to characterize the 7 sites of video sampling performed in 2018 at Silverfish Bay and relative measured abundance metrics. Geomorph = geomorphology; Mean N = Mean Number; TFA = Time of First Arrival.

\begin{tabular}{ccccccccc}
\hline Site \# & $\begin{array}{c}\text { Set Duration } \\
\text { (hh:mm:ss) }\end{array}$ & $\begin{array}{c}\text { Depth } \\
(\mathbf{m})\end{array}$ & Substrate & Benthos & Geomorph. & CPUE & MeanN & $\begin{array}{c}\text { TFA } \\
(\mathbf{m i n})\end{array}$ \\
\hline 01 & $01: 19: 38$ & 258 & mixed & $80 \%$ & Ridge & 0.75 & 1 & 8.2 \\
02 & $05: 38: 43$ & 356 & soft & $40 \%$ & Ridge & 0.53 & 0.6 & 238.8 \\
03 & $06: 01: 05$ & 475 & mixed & $80 \%$ & Trench & 0 & 0 & - \\
04 & $06: 29: 34$ & 303 & mixed & $70 \%$ & Ridge & 0 & 0 & - \\
05 & $01: 59: 25$ & 179 & mixed & $90 \%$ & Ridge & 0 & 0 & 1.4 \\
06 & $06: 14: 34$ & 543 & soft & $10 \%$ & Trench & 1.92 & 60.3 \\
07 & $05: 27: 00$ & 390 & soft & $60 \%$ & Ridge & 0.37 & 0.4 & 167.2 \\
\hline
\end{tabular}

The values of CPUE and MeanN at the sites of sighting were strongly correlated $(r=0.95, p<0.01)$, suggesting they may each be indicating abundance even though sample size is low. TFA did not follow the trend of the other two metrics.

\subsection{Other Fish Species Recorded by BRUV}

While the target species of the work was the Antarctic toothfish, other fish species, representative of the shelf demersal and pelagic assemblages, were recorded by our miniBRUV. Juveniles and a large shoal of adult Antarctic silverfish (Pleuragramma antarctica) were recorded at McMurdo Sound. Juveniles Antarctic silverfish were also often recorded during the mini-BRUV deployments at Silverfish Bay. In this latter area, various Trematomus species were recorded. Trematomus hansoni were often seen approaching the bait, occasionally trying to eat it, or just swimming in the camera field in groups of five or more individuals. Trematomus bernacchii were also recorded around the bait, usually solitary swimming. One Artedidraconidae and one Chionodraco sp. incidentally entered the field of view of the camera; however, they did not show any interest for the bait. A group of Trematomus borchgrevinki was recorded in the upper water column, close to the sea-ice during the deployment and the hauling of the BRUV.

\section{Discussion}

The Antarctic toothfish is a high trophic level predator in the Antarctic ecosystems, utilizing a broad range of habitats during its lifecycle, from the epipelagic realm to benthopelagic slope habitats down to $2000 \mathrm{~m}$ depth [4]. Current understanding on the biology and life cycle of the species mainly relies on fishery-dependent data [2,3], resulting in catchability biases and knowledge gaps. New data on the abundance and distribution of the Antarctic toothfish in coastal shelf areas are required to support population hypotheses and management of this living resource. Large stretches of the coastal shelf areas are datapoor or unexplored, due to the occurrence of fast sea ice that prevents the access of fishing vessels. This holds truth even in regions where the toothfish is historically harvested, such as the Ross Sea region.

We investigated the performance of a BRUV system to collect biological data on the Antarctic toothfish in the data-poor sea-ice covered areas of the Ross Sea region shelf, a region of interest for fishery management and marine conservation. 
BRUV systems were demonstrated to produce results comparable to some fishery-based methods for monitoring trends in the relative abundance [31] and have been proven effective in surveying mobile predators and/or opportunistic scavengers, such as sharks [22,37] and grenadier [49], thus making this sampling technique promising to collect fishery independent data on the predator and scavenger Antarctic toothfish [50]. Prior to the present work, a few attempts were made for the use of BRUV systems in the Antarctic waters. In the West Antarctic Peninsula, a BRUV was used to examine scavenging fauna in relation to the exposure to iceberg scouring within Ryder Bay [26], and a preliminary study was performed on the use of baited cameras mounted on a rather large autonomous lander (Aberdeen University Deep Ocean Submersible (AUDOS)) to estimate the abundance and size of the co-generic Patagonian toothfish D. eleginoides in sub-Antarctic areas [24]. In both cases, the activities were in open waters, with rather voluminous baited camera systems deployed from boats and set on the sea bottom.

The study on D. eleginoides, while demonstrating the general feasibility of toothfish abundance estimation by BRUV, stressed the need for improvements in the design of the system and suggested the use of short-term deployment times (2-3 h). Following those recommendations, in the present study, the efforts were put in the design and configuration of the system, as well as in the optimization of the protocol.

In line with recent trends towards the development of miniaturized deep-sea cameras targeting the reduction of size and costs [51], our BRUV system was developed to be essential in the design and small in size and set up with the camera view facing vertically downward. The majority of BRUVS set-ups used a horizontal camera arrangement, and only the $14 \%$ had a vertical orientation pointing down to the seafloor [21]. The vertical camera setting is underused because some species seem reluctant in entering the vertical field of view, most likely due to the perceived confined space under the camera, emphasized by the occurrence of large aluminium frames. Our essential BRUV system does not present any frames or bait arms (the bait is set close to the weight connected by a short piece of fishing line), while camera and light are suspended at about $2 \mathrm{~m}$ from the seafloor. Such a setting did not seem to affect the fish behaviour, and Antarctic toothfish were recorded swimming around the bait for quite long time, about $8 \mathrm{~min}$ on average, and up to $44 \mathrm{~min}$. In this configuration, the mini-BRUV system was proven suitable for deployment through holes in the sea ice of relatively small diameter (even less than $40 \mathrm{~cm}$ ), significantly reducing the workload and logistics required to perform surveys from the sea ice. Furthermore, it was easily transportable and light enough to be set and hauled by hand.

In order to optimize the protocol, soak time was carefully considered. During the field work at McMurdo Sound, the association of BRUV work to the longline activities imposed long duration of deployments, with soak times of over $20 \mathrm{~h}$. However, the a posteriori analysis of the videos clearly demonstrated that long deployments are unnecessary and that soak time from one to six hours is ideal, allowing both data collection and multiple deployments in a short period. Remarkably, no decay in the effect of the bait was recorded in such a timeframe, and Antarctic toothfish were spotted approaching the bait until hour six. Overall, the effectiveness of short-term deployments to monitor Dissostichus species [24] is confirmed; one-hour video record is likely sufficient to collect baseline data; however, deployments up to six hours might allow for a more precise calculation of relative abundance metrics.

A critical point for the optimization of protocols for BRUV observations is the effectiveness of the bait in attracting the target species, which has repercussions on abundance metrics $[39,52,53]$. Here, the bait was a squid routinely used in the Antarctic toothfish longline fishery. The behaviour of the fish at the bait supports a positive olfactory response and searching behaviour in the odour plume, which is expected based on their olfactory capabilities [16]. The fish were observed approaching slowly to the bait, often sliding it along their flank and eventually grasping it in their jaws. Dissostichus eleginoides individuals were reported to be attracted by the bait but never observed to investigate closely or attempt to take the bait [24]. Such distinct behaviours could be related to differences in 
the BRUV configurations. In particular, the essential design of our mini-BRUV was likely perceived by fish as not disturbing and did not arise suspicion on fish. However, it is also worth noting that the work on D. eleginoides was performed in a commercially longlined, plenty-of-food area, while our activity on $D$. mawsoni was performed in areas not accessible to fishing vessels and, in the case of Terra Nova Bay, in the frame of a specially protected area (ASPA 173) where disturbance of anthropic origin was minimal.

The effectiveness of the bait in attracting Antarctic toothfish individuals was also supported by the absence of any fish record in the negative controls held with no bait. The effect of other potential attractants related to the BRUV, such as light and noise, or presence of other organisms around the system, seems negligible. Interestingly, while the use of intense light in BRUV is usually discouraged due to possible flash induced bait shyness [24], the Antarctic toothfish individuals observed under the light of our mini-BRUV did not show any discomfort; on the contrary, some of them were attracted by the light and occasionally were recorded swimming upward pointing the lamp (Video S1).

The design and configuration of our mini-BRUV allowed to collect high-quality video imagery of 60 Antarctic toothfish in 13 deployments. To the best of our knowledge, only brief images of a single Antarctic toothfish, incidentally acquired during a video survey in McMurdo Sound [54], and sparse snapshots of fish from cameras attached to Weddell seals [55] were available prior to this work. Here, the high quality of the videos is coupled with high number of records, thus providing valuable new documentation of the Antarctic toothfish in its natural habitat (Video S1). Owing to the quality of the videos and the low number of individuals occurring in the field of view simultaneously, identification was possible for all the individuals. Scars and unique colour patterns present were effective natural markings to distinguish individuals and, although the persistence over time of those markings is unknown, at least they can be used as effective markers within a single deployment. This facilitated the abundance metric calculations, and biases related to re-counting were avoided.

Two of the three used metrics, CPUE and MeanN, resulted strongly correlated, but their efficacy remains to be confirmed with additional data. The possibility to use MeanN as a proper abundance metric would allow to avoid the identification of single individuals, a difficult and time-consuming step necessary for the calculation of CPUE, thus significantly reducing the time allocated to video processing, which is necessary. This would foster the application of the methodology and the collection of a large number of recordings. Among the other metrics considered, the time of first arrival (TFA) was successfully adopted for the congeneric Patagonian toothfish [24]. Such a metric is powerful when integrated with data on the current and fish swimming speed [51]. However, in the present study, due to the lack of current speed measurements and reliable estimate of the speed of fish attracted by the bait, the TFA could not be standardized, and its informative value as proxy of Antarctic toothfish abundance was poor.

The low number of BRUV deployments for comparison with longline catch in McMurdo Sound prevented any robust calculation of metrics or trends. However, at the stations where the catch with longlines was the highest, Antarctic toothfish individuals appeared in the field of view of the camera during the first hour, supporting the relation between fish catches and BRUV counts. A relation between the calculated BRUV abundance metrics and the longline catch rates seems to be occurring, but further comparative investigations are needed to provide statistical support to this observation.

Besides quantifying the relative abundance and distribution of target species, the BRUV systems hold potential to generate a variety of data; characterize benthic habitats; and assess functional diversity, body sizes, and animal behaviours [22], thus, in turn, facilitating investigation of fish-habitat relationship [56]. We collected basic information on the sea bottom features (composition and granulometry) from all videos and conducted a preliminary study to investigate the relationship between physical characteristics of the environment and presence of Antarctic toothfish at Terra Nova Bay. Regardless of depth and geomorphology, toothfish were recorded at three stations characterized by soft bottom 
and relatively low benthos coverage and only one station with a mixed sea bottom. The preference toward soft sea bottom seems confirmed by the data from McMurdo Sound, where toothfish were BRUV sampled only in soft bottom areas.

Another interesting observation from the videos is the size of the Antarctic toothfish at Terra Nova Bay, larger than that expected for the Ross Sea shelf area [3], with prevalence of individuals between 100 and $130 \mathrm{~cm}$ length (55.6\%) and some larger mature ones (27.7\%). It is worth noting that the fish sampled by BRUV at McMurdo Sound are overall smaller than the ones observed at Terra Nova Bay. Despite being a point observation, this aspect might have repercussions on current population hypothesis for the Ross Sea and deserves further investigation.

Overall, the results of our trials, encourage the use of BRUV to study the abundance and distribution of Antarctic toothfish in sea-ice covered areas but also as a valid investigation tool for field work in other areas around the Antarctic continent, whether or not seasonally covered with fast ice. Here, clues for the optimization of the sampling protocols, including information on the bait and optimal soak time, are provided. Furthermore, this study, although preliminary, identified gaps in the knowledge base that could be addressed by the use of BRUV, including habitat preferences of the Antarctic toothfish and size distribution in ice-covered shelf areas. As a side information, our mini-BRUV was proven effective in attracting fish species other than our target species and could thus be used to study densities and behaviour of those species, as well as fish assemblages.

Our pilot investigation allowed to highlight that some improvements should be considered in future studies. In particular, the addition of a current meter would allow to consider current speed that might influence the odour dispersal and lead to bias in the metrics calculations, especially TFA [24]. Another important improvement would be the addition of coupled lasers pointer with parallel light beams, which would allow a more accurate calculation of the fish length and evaluation of the size distribution for the species. Furthermore, the laser pointers would aid in estimating the fish swimming speed, another key element that influences the TFA and, consequently, the abundance estimate. The setting up on the BRUV of sensors for water parameters might add relevant environmental information in support of habitat preferences evaluations. The description of water mass preferences of adult toothfish might provide relevant information on the movements of adults on the continental shelf, with repercussion on the management of the species. The use of non-extractive methods, including BRUV, is of particular relevance in the Ross Sea region, where the largest MPA of the world has recently been established and where this tool can be used in many more applications to study target species but also assemblages and behaviour, supporting research and monitoring in the area.

Supplementary Materials: The following are available online at https:/ / www.mdpi.com/2077-131 2/9/3/255/s1. Video S1: Behaviour of Antarctic toothfish (video recorded on November 14, 2018, at Site 06, Terra Nova Bay). Table S2: Summary table.

Author Contributions: Conceptualization, L.G. and M.V.; methodology, D.D.B. and E.C.; validation, E.P.; formal analysis, D.D.B.; investigation, D.D.B., E.C., S.C., and S.J.P.; resources, S.C.; data curation, D.D.B.; writing—original draft preparation, D.D.B.; writing—review and editing, E.P., L.G., and S.J.P.; supervision, L.G., S.J.P., and M.V.; project administration, L.G.; funding acquisition, L.G., M.V., and S.J.P. All authors have read and agreed to the published version of the manuscript.

Funding: This research was funded by the Italian National Programme for Antarctic Research (projects MIUR-PNRA 2015/B1.02 - DISMAS, MIUR-PNRA 2016/AZ1.19 - PILOT) and by the New Zealand Ministry for Primary Industries (project ANT201501) and Antarctica New Zealand.

Institutional Review Board Statement: In situ activities were carried out at McMurdo Sound in accordance with permit AMLR15/R01/Parker/K086 issued by the New Zealand government under the Antarctic Marine Living Resources (AMLR) Act 1981 and at Terra Nova Bay in compliance with the Protocol of Environmental Protection to the Antarctic Treaty, Annex II, Art.3, in the frame of PNRA Research Projects. 
Data Availability Statement: The data presented in this study are available in article and in the Supplementary Materials.

Acknowledgments: We thank the CCAMLR EMM and FSA Working Groups participants, with whom the work was discussed, for fruitful suggestions on the refinement of the technique. The participation of Davide Di Blasi in the CCAMLR Working Groups was allowed by the CCAMLR Scholarship for early career researchers during years 2018-2019. Part of the work was carried out during his PhD at the University of Genoa. We thank the three anonymous reviewers for their thoughtful comments and constructive remarks.

Conflicts of Interest: The authors declare no conflict of interest. The funders had no role in the design of the study; in the collection, analyses, or interpretation of data; in the writing of the manuscript; or in the decision to publish the results.

\section{References}

1. Long, R.D.; Charles, A.; Stephenson, R.L. Key principles of marine ecosystem-based management. Mar. Policy 2015, 57, 53-60. [CrossRef]

2. Mormede, S.; Dunn, A.; Hanchet, S.M. A stock assessment model of Antarctic toothfish (Dissostichus mawsoni) in the Ross Sea region incorporating multi-year mark-recapture data. CCAMLR Sci. 2014, 21, 39-62.

3. Hanchet, S.M.; Dunn, A.; Parker, S.J.; Horn, P.L.; Stevens, D.W.; Mormede, S. The Antarctic toothfish (Dissostichus mawsoni): Biology, ecology, and life history in the Ross Sea region. Hydrobiologia 2015, 761, 397-414. [CrossRef]

4. Hanchet, S.M.; Rickard, G.J.; Fenaughty, J.M.; Dunn, A.; Williams, M.J. A hypothetical life cycle for Antarctic toothfish Dissostichus mawsoni in Antarctic waters of CCAMLR Statistical Area 88. CCAMLR Sci. 2008, 15, 35-54.

5. Parker, S.J.; Stevens, D.W.; Ghigliotti, L.; La Mesa, M.; Di Blasi, D.; Vacchi, M. Winter spawning of Antarctic toothfish Dissostichus mawsoni in the Ross Sea region. Antarctic Sci. 2019, 31, 243-253. [CrossRef]

6. Eastman, J.T.; DeVries, A.L. Aspects of body size and gonadal histology in the Antarctic toothfish, Dissostichus mawsoni, from McMurdo Sound, Antarctica. Polar Biol. 2000, 23, 189-195. [CrossRef]

7. Ramorino, M.C. Rapporto sulla Campagna Antartica Estate Australe 2003-2004; Diciannovesima spedizione. In PNRA Programma Nazionale di Ricerche in Antartide; Progetto Antartide, Final Report; Consortium for the Implementation of National Research Programmes in Antarctica: Roma, Italy, 2004; pp. 71-75.

8. Ainley, D.G.; Nur, N.; Eastman, J.T.; Ballard, G.; Parkinson, C.L.; Evans, C.W.; DeVries, A.L. Decadal trends in abundance, size and condition of Antarctic toothfish in McMurdo Sound, Antarctica, 1972-2011. Fish Fish 2013, 14, 343-363. [CrossRef]

9. Parker, S.J.; Mormede, S.; DeVries, A.; Hanchet, S.M.; Eisert, R. Have Antarctic toothfish returned to McMurdo Sound? Antarctic Sci. 2016, 28, 29-34. [CrossRef]

10. Parker, S.J.; Mormede, S.; Hanchet, S.M.; DeVries, A.; Canese, S.; Ghigliotti, L. Monitoring Antarctic toothfish in McMurdo Sound to evaluate the Ross Sea region Marine Protected Area. Antarctic Sci. 2019, 31, 195-207. [CrossRef]

11. Mallet, D.; Pelletier, D. Underwater video techniques for observing coastal marine biodiversity: A review of sixty years of publications (1952-2012). Fish. Res. 2014, 154, 44-62. [CrossRef]

12. Ono, K.; Kotwicki, S.; Dingsør, G.E.; Johnsen, E. Multispecies acoustic dead-zone correction and bias ratio estimates between acoustic and bottom-trawl data. ICES J. Mar. Sci. 2018, 75, 361-373. [CrossRef]

13. O'Driscoll, R.L.; Ladroit, Y.; Parker, S.J.; Vacchi, M.; Canese, S.; Ghigliotti, L.; Dunford, A.J.; Mormede, S. Acoustic deployments reveal Antarctic silverfish under ice in the Ross Sea. Antarctic Sci. 2018, 30, 345-353. [CrossRef]

14. Cappo, M.; Harvey, E.; Shortis, M. Counting and Measuring Fish with Baited Video Techniques-An Overview. In Australian Society for Fish Biology Workshop Proceedings; Australian Society for Fish Biology: Tasmania, Australian, 2006; Volume 1, pp. 101-114.

15. Bassett, D.K.; Montgomery, J.C. Investigating nocturnal fish populations in situ using baited underwater video: With special reference to their olfactory capabilities. J. Exp. Mar. Biol. Ecol. 2011, 409, 194-199. [CrossRef]

16. Ferrando, S.; Amaroli, A.; Gallus, L.; Di Blasi, D.; Carlig, E.; Rottigni, M.; Vacchi, M.; Parker, S.J.; Ghigliotti, L. Olfaction in the Antarctic toothfish Dissostichus mawsoni: Clues from the morphology and histology of the olfactory rosette and bulb. Polar Biol. 2019, 42, 1081-1091. [CrossRef]

17. Carlig, E.; Di Blasi, D.; Ghigliotti, L.; Pisano, E.; Faimali, M.; O’Driscoll, R.; Parker, S.; Vacchi, M. Diversification of feeding structures in three adult Antarctic nototheniid fish. Polar Biol. 2018, 41, 1707-1715. [CrossRef]

18. Bailey, D.M.; King, N.J.; Priede, I.G. Cameras and carcasses: Historical and current methods for using artificial food fall to study deepwater animals. Mar. Ecol. Prog. Ser. 2007, 350, 179-191. [CrossRef]

19. Dunlop, K.M.; Marian Scott, E.; Parsons, D.; Bailey, D.M. Do agonistic behaviours bias baited remote underwater video surveys of fish? Mar. Ecol. 2015, 36, 810-818. [CrossRef]

20. Ellis, D.M.; DeMartini, E.E. Evaluation of a video camera technique for indexing the abundance of juvenile pink snapper, Pristipomoides filamentosus, and other Hawaiian insular shelf fishes. Fish B-NOAA 1995, 93, 67-77.

21. Whitmarsh, S.K.; Fairweather, P.G.; Huveneers, C. What is Big BRUVver up to? Methods and uses of baited underwater video. Rev. Fish Biol. Fisher. 2017, 27, 53-73. [CrossRef] 
22. Devine, B.M.; Wheeland, L.J.; Fisher, J.A. First estimates of Greenland shark (Somniosus microcephalus) local abundances in Arctic waters. Sci. Rep. 2018, 8, 1-10. [CrossRef] [PubMed]

23. Devine, B.M.; Wheeland, L.J.; de Moura Neves, B.; Fisher, J.A. Baited remote underwater video estimates of benthic fish and invertebrate diversity within the eastern Canadian Arctic. Polar Biol. 2019, 42, 1323-1341. [CrossRef]

24. Yau, C.; Collins, M.A.; Bagely, P.M.; Everson, I.; Nolan, C.P.; Priede, I.G. Estimating the abundance of Patagonian toothfish Dissostichus eleginoides using baited cameras: A preliminary study. Fish. Res. 2001, 51, 403-408. [CrossRef]

25. Smale, D.A.; Barnes, D.K.A.; Fraser, K.P.P.; Mann, P.J.; Brown, M.P. Scavenging in Antarctica: Intense variation between sites and seasons in shallow benthic necrophagy. J. Exp. Mar. Biol. Ecol. 2007, 349, 405-417. [CrossRef]

26. Dunlop, K.M.; Barnes, D.K.A.; Bailey, D.M. Variation of scavenger richness and abundance between sites of high and low iceberg scour frequency in Rider Bay, west Antarcic Peninsula. Polar Biol. 2014, 37, 1741-1754. [CrossRef]

27. Vanney, J.R.; Falconer, R.K.H.; Johnson, G.L. Geomorphology of the Ross Sea and adjacent oceanic provinces. Mar. Geol. 1981, 41, 73-102. [CrossRef]

28. Langhorne, P.J.; Hughes, K.G.; Gough, A.J.; Smith, I.J.; Williams, M.J.M.; Robinson, N.J.; Stevens, C.L.; Rack, W.; Price, D.; Leonard, G.H.; et al. Observed platelet ice distributions in Antarctic sea ice: An index for ocean-ice shelf heat flux. Geophys. Res. Lett. 2015, 42, 5442-5451. [CrossRef]

29. Hoppmann, M.; Richter, M.E.; Smith, I.J.; Jendersie, S.; Langhorne, P.J.; Thomas, D.N.; Dieckmann, G.S. Platelet ice: The Southern Ocean's hidden ice: A review. Ann. Glaciol. 2020, 1-28. [CrossRef]

30. Malandrino, M.; Abollino, O.; Buoso, S.; Casalino, C.E.; Gasparon, M.; Giacomino, A.; La Gioia, C.; Mentasti, E. Geochemical characterisation of Antarctic soils and lacustrine sediments from Terra Nova Bay. Microchem. J. 2009, 92, 21-31. [CrossRef]

31. Brooks, E.J.; Sloman, K.A.; Sims, D.W.; Danylchuk, A.J. Validating the use of baited remote underwater video surveys for assessing the diversity, distribution and abundance of sharks in the Bahamas. Endanger. Species Res. 2011, 13, 231-243. [CrossRef]

32. Barord, G.J.; Dooley, F.; Dunstan, A.; Ilano, A.; Keister, K.N.; Neumeister, H.; Preuss, T.; Schoepfer, S.; Ward, P.D. Comparative population assessments of Nautilus sp. in the Philippines, Australia, Fiji, and American Samoa using baited remote underwater video systems. PLoS ONE 2014, 9, e100799. [CrossRef]

33. Stobart, B.; Díaz, D.; Álvarez, F.; Alonso, C.; Mallol, S.; Goñi, R. Performance of baited underwater video: Does it underestimate abundance at high population densities? PLoS ONE 2015, 10, e0127559. [CrossRef] [PubMed]

34. Langlois, T.J.; Fitzpatrick, B.R.; Fairclough, D.V.; Wakefield, C.B.; Hesp, S.A.; McLean, D.L.; Harvey, E.S.; Meeuwig, J.J. Similarities between line fishing and baited stereo-video estimations of length-frequency: Novel application of kernel density estimates. PLoS ONE 2012, 7, e45973. [CrossRef]

35. Lowry, M.; Folpp, H.; Gregson, M.; Suthers, I. Comparison of baited remote underwater video (BRUV) and underwater visual census (UVC) for assessment of artificial reefs in estuaries. J. Exp. Mar. Biol. Ecol. 2012, 416, 243-253. [CrossRef]

36. White, J.; Simpfendorfer, C.A.; Tobin, A.J.; Heupel, M.R. Application of baited remote underwater video surveys to quantify spatial distribution of elasmobranchs at an ecosystem scale. J. Exp. Mar. Biol. Ecol. 2013, 448, 281-288. [CrossRef]

37. Santana-Garcon, J.; Newman, S.J.; Harvey, E.S. Development and validation of a mid-water baited stereo-video technique for investigating pelagic fish assemblages. J. Exp. Mar. Biol. Ecol. 2014, 452, 82-90. [CrossRef]

38. Udyawer, V.; Cappo, M.; Simpfendorfer, C.A.; Heupel, M.R.; Lukoschek, V. Distribution of sea snakes in the Great Barrier Reef Marine Park: Observations from 10 yrs of baited remote underwater video station (BRUVS) sampling. Coral Reefs 2014, 33, 777-791. [CrossRef]

39. Schmid, K.; Reis-Filho, J.A.; Harvey, E.; Giarrizzo, T. Baited remote underwater video as a promising nondestructive tool to assess fish assemblages in clearwater Amazonian rivers: Testing the effect of bait and habitat type. Hydrobiologia 2017, 784, 93-109. [CrossRef]

40. Willis, T.J.; Millar, R.B.; Babcock, R.C. Protection of exploited fish in temperate regions: High density and biomass of snapper Pagrus auratus (Sparidae) in northern New Zealand marine reserves. J. Appl. Ecol. 2003, 40, 214-227. [CrossRef]

41. Cappo, M.; De'ath, G.; Speare, P. Inter-reef vertebrate communities of the Great Barrier Reef Marine Park determined by baited remote underwater video stations. Mar. Ecol. Prog. Ser. 2007, 350, 209-221. [CrossRef]

42. Harvey, E.S.; Cappo, M.; Butler, J.J.; Hall, N.; Kendrick, G.A. Bait attraction affects the performance of remote underwater video stations in assessment of demersal fish community structure. Mar. Ecol. Prog. Ser. 2007, 350, 245-254. [CrossRef]

43. Colton, M.A.; Swearer, S.E. A comparison of two survey methods: Differences between underwater visual census and baited remote underwater video. Mar. Ecol. Prog. Ser. 2010, 400, 19-36. [CrossRef]

44. Gladstone, W.; Lindfield, S.; Coleman, M.; Kelaher, B. Optimisation of baited remote underwater video sampling designs for estuarine fish assemblages. J. Exp. Mar. Biol. Ecol. 2012, 429, 28-35. [CrossRef]

45. Campbell, M.D.; Pollack, A.G.; Gledhill, C.T.; Switzer, T.S.; DeVries, D.A. Comparison of relative abundance indices calculated from two methods of generating video count data. Fish. Res. 2015, 170, 125-133. [CrossRef]

46. Cappo, M.; Harvey, E.; Malcolm, H.; Speare, P. Potential of Video Techniques to Monitor Diversity, Abundance and Size of Fish in Studies of Marine Protected Areas. In Aquatic Protected Areas. What Works Best and How Do We Know? Beumer, J.P., Grant, A., Smith, D.C., Eds.; Australian Society for Fish Biology: Saint Lucia, Australia, 2003; Volume 1, pp. 455-464.

47. Cappo, M.; Speare, P.; De'ath, G. Comparison of baited remote underwater video stations (BRUVS) and prawn (shrimp) trawls for assessments of fish biodiversity in inter-reefal areas of the Great Barrier Reef Marine Park. J. Exp. Mar. Biol. Ecol. 2004, 302, 123-152. [CrossRef] 
48. Stoner, A.W.; Laurel, B.J.; Hurst, T.P. Using a baited camera to assess relative abundance of juvenile Pacific cod: Field and laboratory trials. J. Exp. Mar. Biol. Ecol. 2008, 354, 202-211. [CrossRef]

49. Priede, I.G.; Merrett, N.R. Estimation of abundance of abyssal demersal fishes; a comparison of data from trawls and baited cameras. J. Fish Biol. 1996, 49, 207-216. [CrossRef]

50. Roberts, J.; Xavier, J.C.; Agnew, D.J. The diet of toothfish species Dissostichus eleginoides and Dissostichus mawsoni with overlapping distributions. J. Fish Biol. 2011, 79, 138-154. [CrossRef] [PubMed]

51. Phillips, B.T.; Licht, S.; Haiat, K.S.; Bonney, J.; Allder, J.; Chaloux, N.; Shomberg, R.; Noyes, T.J. DEEPi: A miniaturized, robust, and economical camera and computer system for deep-sea exploration. Deep. Sea. Res. Pt I 2019, 153, 103136. [CrossRef]

52. Wraith, J.; Lynch, T.; Minchinton, T.; Broad, A.; Davis, A. Bait type affects fish assemblages and feeding guilds observed at baited remote underwater video stations. Mar. Ecol. Prog. Ser. 2013, 477, 189-199. [CrossRef]

53. Jones, R.E.; Griffin, R.A.; Januchowski-Hartley, S.R.; Unsworth, R.K.F. The influence of bait on remote video observations in shallow-water coastal environments associated with the North-Eastern Atlantic. Peer] 2020, 8, e9744. [CrossRef]

54. Eastman, J.T.; Barry, J.P. Underwater video observation of the Antarctic toothfish Dissostichus mawsoni (Perciformes: Nototheniidae) in the Ross Sea, Antarctica. Polar Biol. 2002, 25, 391-395. [CrossRef]

55. Fuiman, L.; Davis, S.; Williams, T. Behavior of midwater fishes under the Antarctic ice: Observations by a predator. Mar. Biol. 2002, 140, 815-822. [CrossRef]

56. Langlois, T.; Goetze, J.; Bond, T.; Monk, J.; Abesamis, R.A.; Asher, J.; Barrett, N.; Bernard, A.T.F.; Bouchet, P.J.; Birt, M.J.; et al. A field and video annotation guide for baited remote underwater stereo-video surveys of demersal fish assemblages. Methods Ecol. Evol. 2020, 11, 1401-1409. [CrossRef] 